\title{
Sustainable quality of conveyor belts using an integrated knowledge system to support decision-making
}

\author{
Daniela MARASOVÁ1*, Katarína TEPLICKÁ ${ }^{2}$, Peter BOKŠA A ${ }^{3}$, Róbert REHÁK ${ }^{4}$ \\ and Zoltán SZALAY 5
}

Authors' affiliations and addresses:

${ }^{1}$ Technical university of Košice, Faculty BERG, Institute of Logistics and Transport, Park Komenského 14, Košice, Slovakia

e-mail: daniela.marasova@tuke.sk

${ }^{2}$ Technical university of Košice, Faculty BERG, Institute of Earth resources, Department of Management, Park Komenského 19, Košice, Slovakia

e-mail: katarina.teplicka@tuke.sk

${ }^{3}$ Technical university of Košice, Faculty BERG, Institute of Logistics and Transport, Park Komenského 14,

Košice, Slovakia

e-mail: peter.boksa@tuke.sk

${ }^{4}$ University of Economics in Bratislava, Faculty of commerce, Departmnet of marketing, Dolnozemská cesta 1, Bratislava, Slovakia

e-mail: robert.rehak@euba.sk

${ }^{5}$ University of Presov, Faculty of management, Departmnet of Accounting and Controlling,

Konštantínová 16, Prešov, Slovakia

e-mail: zszalay12@gmail.com

\section{*Correspondence:}

Daniela Marasová, Technical university, Faculty BERG, Institute of Logistics and Transport, Park Komenského

14, Košice, Slovakia

tel.: +421556023125

e-mail: daniela.marasova@tuke.sk

Funding information:

VEGA $1 / 0577 / 17$

APVV-18-0248

\section{Acknowledgement:}

This contribution was created with the support of projects VEGA 1/0577/17 titled "Transfer of knowledge from laboratory experiments and mathematical models in the creation of a knowledge based system for assessing the quality environmentally friendly conveyor belts

", and with the support from the project titled APVV-180248 "Smart belt conveyors ".

How to cite this article:

Marasová, D., Teplická, K., Bokša, P., Rehák, R. and Szalay, Z. (2021). Sustainable quality of conveyor belts using an integrated knowledge system to support decision-making. Acta Montanistica Slovaca, Volume 26 (1), 117-126

DOI:

https://doi.org/10.46544/AMS.v26i1.10

\begin{abstract}
Environmentally friendly conveyor belts are a modification of conventional conveyor belts. Conveyor belts of the Ecotubelt type enclosed in the shape of a pipe are the most important construction element of hose conveyors, which represent an ecological replacement of classic belt conveyors. Their closed conveyor belt in the shape of a hose allows you to transport material with minimal environmental pollution around the conveyor. A long-term problem for the users of these conveyor belts in the world is their maximum use with regard to their service life within the life cycle of the equipment that uses the conveyor belts. In order to achieve a sustainable quality of conveyor belts related to their service life, it is necessary to propose new procedures for evaluating the quality of conveyor belts in terms of their performance. The object of the research is closed conveyor belts of the Ecotubelt type with special construction. The aim of the research is aimed at gaining comprehensive knowledge about the performance of non-traditional closed conveyor belts in order to achieve their sustainable quality. The article presents a new approach to the evaluation of the quality of the Ecotubelt type conveyor belt using the concept of a knowledge system integrating multidisciplinary knowledge from rubber technologies, the results of laboratory and simulation experiments, as well as mathematical models. The integrated knowledge system includes quality-oriented subsystems within products, processes, services. The result of the model is an economic indicator (TCO) Total Cost Over ship index, which expresses the quality index for the purchase and use of a conveyor belt. The function of the proposed knowledge system for assessing the quality of the conveyor belt is to provide the user with adequate information from a huge amount of data and information, which will enable him to achieve a sustainable quality of classic open as well as closed conveyor belts.
\end{abstract}

\section{Keywords}

conveyor belts, service life, performance, integrated knowledge system, failures, decision 


\section{Introduction}

The extraction of minerals has adverse effects on the environment and human health. The mining industry is trying to apply new approaches to improves the sustainability performance of a mining process. Moreau (2020) focuses on comparing machine fuel efficiency, mine site energy consumption, and length of mine-life for an underground metal mine operating with either manual or automated equipment to investigate their effects on the environment. Environmental economics is increasingly being used to evaluate projects, estimate environmental responsibility, design available instruments on the market. Menegaki et.al. (2020) show that virtually all economic valuation techniques have been implemented to assess, in terms of monetary, the environmental impacts of mining. In compliance with ecological policies, activities undertaken by surface mines in relation to environmental protection should be comprehensive and must take into account the principle of sustained development Bortnowski, (2021). It is important for the sustainability of the mining industry to implement the raw materials policy of the country. Bednárová et al. (2020) analyzed the legal environment and created a set of critical areas of the raw materials policy of the Slovak Republic. At the same time, they have made a recommendation to be included in legislative proposals in the area of raw materials policy. To avoid destroying the ecological environment in the utilization process of mineral resources is need to the applicate concept of cleaner production (CP). The assessment of cleaner production is an important and successful tool for addressing the conflict between economic growth and environmental pollution. Hilson (2003) examines the concepts of "cleaner production (CP)" and "pollution prevention" in the mining context. Tahir, Zeeshan (2021) developed cleaner production in many gold mines to achieve the goal of sustainable development. Conveyor belts enclosed in the shape of a pipe (pipe conveyor) meet the requirements of the cleaner production $(\mathrm{CP})$ concept for the transport of bulk and piece material, contaminated waste, wood chips, and other materials. When applied in the process of extraction and processing of minerals, they represent a solution for the elimination of ecological burden for the surrounding environment (Grujič, 2011). The potential of pipe conveyors is big; it overcomes the shortcomings of the traditional belt conveyor, such as the susceptibility of generating dust, the vulnerability to which it is hampered by spatial restrictions, and the small turning inclination angle. Many countries have proposed the use of environmentally friendly pipe belt conveyors to reduce the environmental pollution from the conveying process (Barburski, 2015). Sazambayeva (2017) and Zamiralova (2017) describe the principle of work, advantages, and disadvantages of hose conveyors. Caban et al. (2016) evaluated the advantages and disadvantages of hose conveyors using multi-criteria evaluation methods. A problem in the operation of the pipe conveyor is the uneven distribution of pressure in the conveyor belt due to its winding into the shape of the pipe. Wang (2019) provides the results of measuring this pressure in coal transportation. Classic belt conveyors with track lengths of several hundred meters or tens of kilometres are a source of noise. Pipe conveyors have a larger number of rollers in an annular roller stand when the upper and lower branches are closed to the pipeline and are a greater source of noise than conventional conveyors. Sawicki (2016), Ladányi (2016), Bortnowski (2021) are engaged in research into noise emissions from the operation of belt conveyors. The results of their research show that the highest noise emissions occur between the conveyor belt and the support roller from the contact between the conveyor belt and the idler. Impact beds are the largest source of dust. At present, the classic system of impact points is being replaced by a new solution in the form of impact beds formed by impact rods (Gondek, 2014), (Hapla, 2013). The impact stand ensures sufficient rigidity, flexibility, the ability to guide the conveyor belts in the direction of transport, dampen the kinetic energy and reduce the frictional resistance. Prediction of the failure of hose conveyors in terms of insufficient quality and high dynamic stress of conveyor belts at impact points is very important, especially due to the cost of technological processes. Bugaric (2012) analyzes the loss of production costs caused by the failure of rubber conveyor belts. One of the risk parameters of a given type of conveyor belt is its rapid wear and tear and damage. Hardygora (2015) and Blazej (2017) state that the quality of conveyor belts is also affected by the quality of connections. From an overview of theoretical knowledge, experimental measurements, and operational experience. Conveyor belt failure depends on insufficient tensile strength of the conveyor belt (Ambriško, 2016), dynamic impact stress at the point of impact of the material on the conveyor belt (Ambriško, 2017), (Grinčová, 2009). This stress depends to a large extent on the construction of the impact point, the actual construction of the belt, and the force ratios in the belt, in the part in which it acts. The assessment of the quality of conveyor belts is possible from several points of view, and many different approaches can be applied to its solution. For conveyor belt operators, the service life within its life cycle is a very important factor in their quality. Product quality plays an important level throughout the life cycle of a conveyor belt. The impact stand ensures sufficient rigidity, flexibility, the ability to guide the conveyor belts in the direction of transport, dampen the kinetic energy and reduce the frictional resistance. Prediction of the failure of hose conveyors in terms of insufficient quality and high dynamic stress of conveyor belts at impact points is very important, especially due to the cost of technological processes. Bugaric (2012) analyzes the loss of production costs caused by the failure of rubber conveyor belts. One of the risk parameters of a given type of conveyor belt is its rapid wear and tear and damage. Hardygora (2015) and Blazej (2017) state that the quality of conveyor belts is also affected by the quality of connections. From an overview of theoretical knowledge, experimental measurements, and operational experience. Conveyor 
belt failure depends on insufficient tensile strength of the conveyor belt (Ambriško, 2016), dynamic impact stress at the point of impact of the material on the conveyor belt (Ambriško, 2017), (Grinčová, 2009). This stress depends to a large extent on the construction of the impact point, the actual construction of the belt, and the force ratios in the belt, in the part in which it acts. The assessment of the quality of conveyor belts is possible from several points of view, and many different approaches can be applied to its solution. For conveyor belt operators, the service life within its life cycle is a very important factor in their quality. Product quality plays an important level throughout the life cycle of a conveyor belt. Czapliczka (2003) has been presented the methodology of optimization of strength properties regarding various belts and their impact on the environment during the entire product life cycle.

\section{Material and Methods}

Conveyor belts of the Ecotubelt type (Fig. 1) enclosed in the shape of a pipe are the most important structural element of hose conveyors, which represent an ecological modification of classic belt conveyors. Eco-friendly pipe conveyor type ECOTUBELT eliminates environmental pollution during the transport of environmentally harmful materials. Conveyor belts consist of 7 important parts: outer cover layer (1), adhesive layer(2), rubber textile insert (3), aramid reinforcement ropes (4), core rubber (5), steel cords (6), inner cover layer (7).

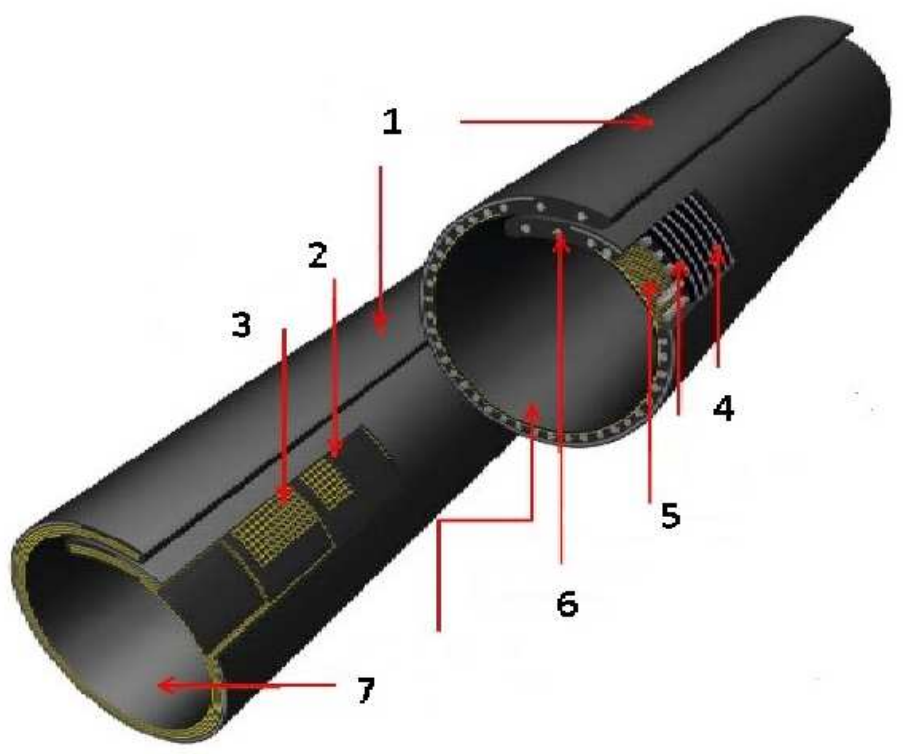

Fig. 1. Construction of a conveyor belt of a hose conveyor Source: http://www.monsterbelt.com/special-conveyor

The skeleton of the conveyor belt consists of several textile inserts or steel cords rubberized with a special rubber compound to ensure adhesion between the inserts or cords and cover layers. Ecological transport of materials by conveyor belts of the ECOTUBELT type is intended for the transport of ecologically harmful materials that cause pollution of the living and working environment. The conveyor belt wound into the shape of a hose transports material with a maximum piece size of 0.3 hose diameter. The Ecotubelt construction consists of a skeleton of two or three inserts (P, EP). The skeleton is protected by rubber cover layers. ECOTUBELT can have cover layers: A - for the transport of abrasive and sharp-edged material of large piece size, at ambient temperature from $-25^{\circ} \mathrm{C}+60^{\circ} \mathrm{C}$, AA - for the transport of very abrasive, sharp-edged material at ambient temperatures from $25^{\circ} \mathrm{C}+60{ }^{\circ} \mathrm{C}$, D - for the transport of hot, granular, and bulk materials with a temperature up to $+125^{\circ} \mathrm{C}$.

The skeleton of the conveyor belt serves to transfer forces from the drive unit via the drive drum to the conveyor belt and subsequently to the transported material. At the same time, it provides the conveyor belt with the necessary strength and durability. Transverse rigidity is ensured by the use of a special carcass construction. The cover layers protect the conveyor belt skeleton against external climatic influences of the environment, mechanical damage, the action of moisture as well as chemical and thermal influences acting on the conveyor belt. Its properties must withstand the aggressive effects of the transported material. The basic parameters of conveyor belts for Ecotubelt hose conveyors are given in Table 1. 
Tab. 1. The basic parameters of conveyor belts ECOTUBELT

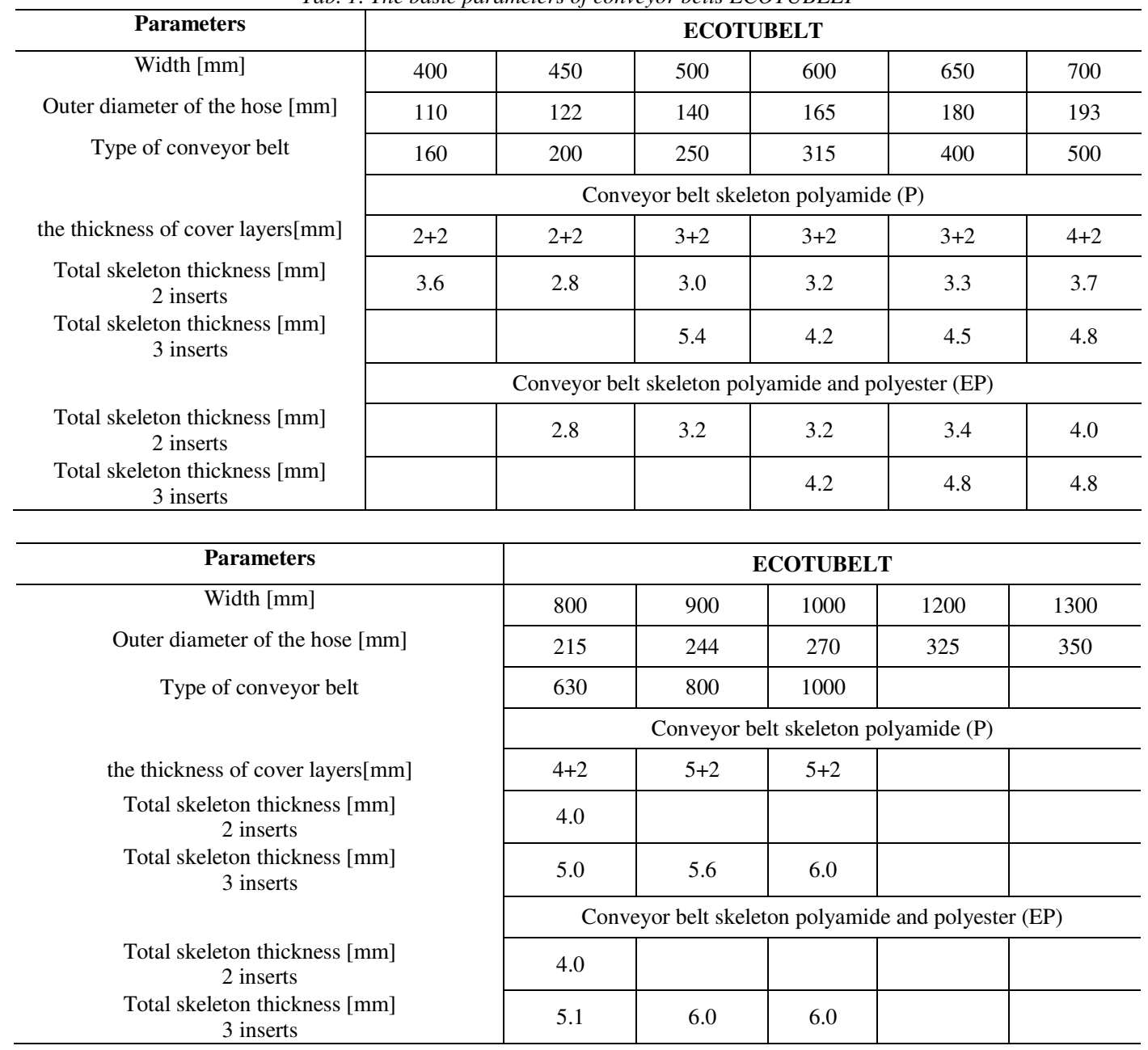

Pipe conveyor (Fig. 2) for the transport of minerals linked to a crusher station at the bottom of the mine allows conveyance over mine slopes with inclinations $\leq$ of $34^{\circ}$ at mine depths of up to $700 \mathrm{~m}$. The transport capacity is up to $5000 \mathrm{t} / \mathrm{h}$, and the primary crushed material can have sizes up to $350 \mathrm{~mm}$. When using pipe conveyors significantly reduced the mining truck fleet and $\mathrm{CO}_{2}$ footprint. Closed-trough transport is environment friendly and safe.

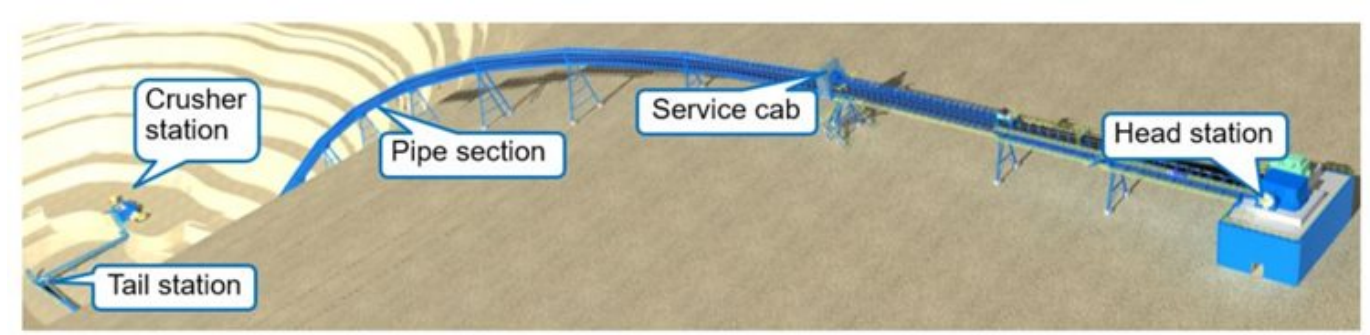

Fig. 2. Pipe conveyor

Source: https://www.matador-belts.com/pages/special_application/ecotubelt/ecotubelt_sk.html

The main disadvantages of the pipe conveyor include their limited service life and the high price of the conveyor belt. Among the factors that most influence the lifetime of conveyor belts is their product, process, and service quality. Defining lifespan is very difficult. It is easier to identify the causes of faults. Disorders are most often caused by wear and fatigue. The most common methods from the field of the theory of mathematical statistics are used in the analysis and evaluation of the quality of conveyor belts in terms of their service life because the occurrence of failures of the conveyor belt and belt conveyor is a stochastic quantity. For evaluation of conveyor belt performance used TCO index. The performance evaluation of rubber conveyor belts is carried out using the Total Cost Overship index (TCO index). Evaluation of the TCO index: The value of the TCO index $<4.258 \%$ while maintaining $5 \%$ of the value of repairs during the service life of 12 months, we can evaluate the quality of 
conveyor belts at a very good level - functional, the operational condition of the conveyor belt. The formula for TCO index:

$$
\text { TCO index }=\frac{x+y}{w} \text {, }
$$

where: TCO index (total cost overship), $x$ - The purchase price in $(\%), y$ - Service price in $(\%)$ of the purchase price, $w$ - service life in months.

The service life in months is calculated from the records on a specific conveyor. Careful inspection and diagnostics of all machine parts of the belt conveyor and thorough rubber maintenance (monitoring of joints, their repair, timely removal of worn parts of the conveyor belt within planned repairs) reduce the risk of secondary failures, thus reducing maintenance costs and unplanned downtime.

\section{Results}

Traditional solution in terms of using physical systems (servers and personal computer) has several disadvantages. Use of hardware virtualization, which is a new technology of the $21^{\text {st }}$ century and which is a suitable and easy-to-use solution for optimizing all of the processes in the mining companies. In addition to information systems (Lukáč, 2020), knowledge systems can also be applied for the needs of evaluating the quality of conveyor belts. Knowledge also plays an important role in the process of obtaining and processing land resources. The ability of the top management of a mining company to effectively use and manage the knowledge of its employees gives it a competitive advantage. Syed et al. (2020) confirmed in their study that knowledge acquisition and dissemination also have a significant positive impact on business innovation. In addition, the application of knowledge mediates the relationship between knowledge generation, knowledge storage, and solid innovation. The development of IT technologies has caused an exponential increase in available information and knowledge, which has led to the creation of knowledge systems. The aim of the research is aimed at gaining comprehensive knowledge about the performance of non-traditional closed conveyor belts in order to achieve their sustainable quality. The paper presents a new approach to the evaluation of the quality of the Ecotubelt type conveyor belt using the concept of a knowledge system integrating multidisciplinary knowledge from rubber technologies, the results of laboratory and simulation experiments, as well as mathematical models. The concept of the knowledge system (Fig. 3) is based on the definitions of knowledge management and DIKW pyramids (data-informationknowledge-wisdom), which are defined by the authors (Girard, 2015; Baldassarre, 2016).

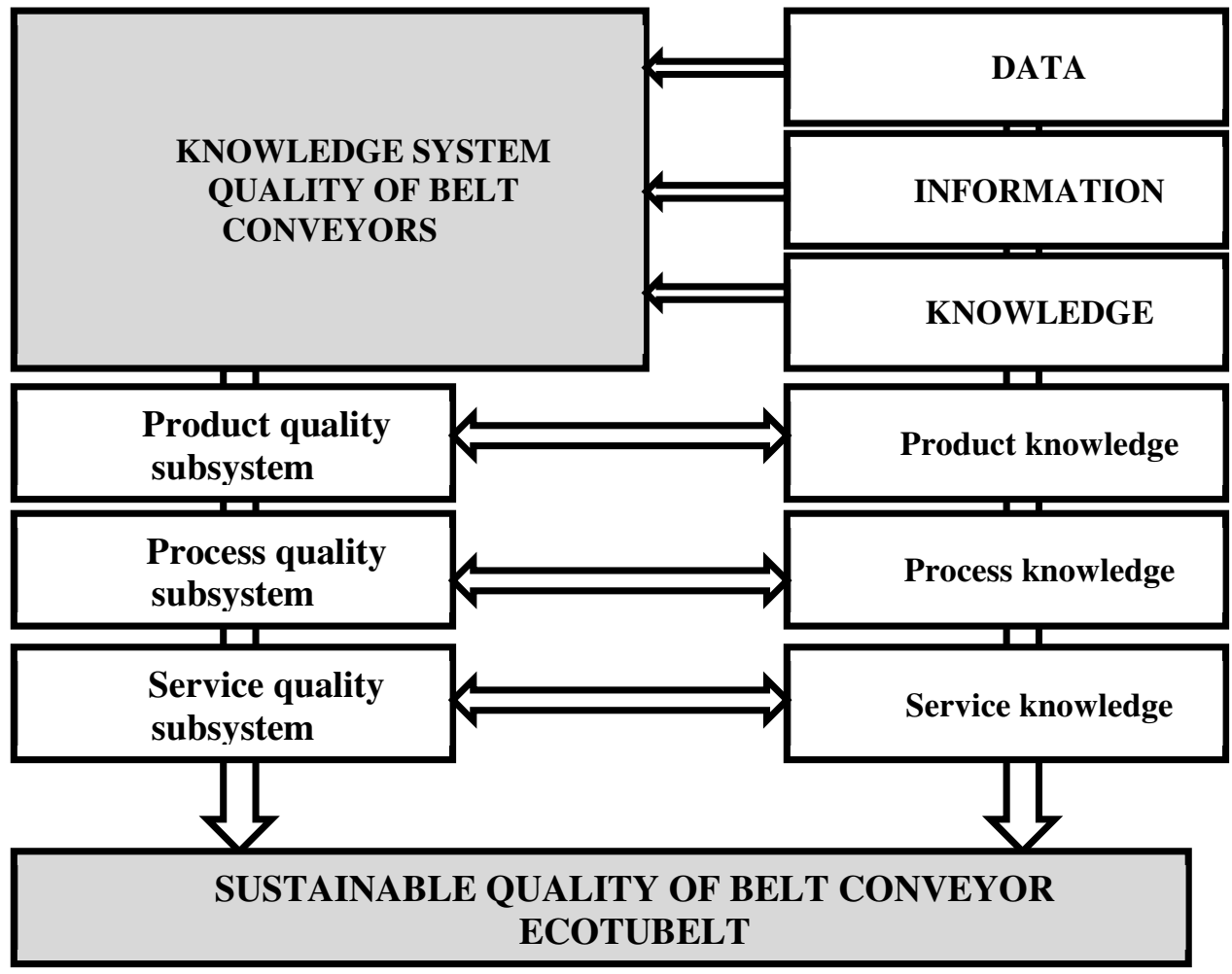

Fig. 3. Proposal of the concept of the knowledge system for belt conveyors quality evaluation Source: own source 
The creation of a knowledge system for assessing the quality of conveyor belts involved the systematic acquisition, analysis, synthesis, and sharing of knowledge and opinions on the nature of quality from the aspect of the life cycle of the conveyor belt. Experience has been implemented to reduce the risk of deciding on the appropriate conveyor belt. The given system design can be considered as a decision tool. The knowledge system for evaluating the quality of conveyor belts is based on the Visual Basic platform with Windows support (Fig. 4). The information provided by the system is a basic decision-making tool for conveyor belt production and sales managers, maintenance managers, service managers in the rubber maintenance of conveyor belts in various industries.

The creation of the system was based on the theory of systems using a logical-mathematical apparatus in order to serve to provide information for quality control of conveyor belts. The information system enables updating and calculations in order to achieve the required goal - evaluation of the quality of conveyor belts. The result of processing data on the transported material, technical parameters of the conveyor, construction, and operating conditions are output information designed for the efficient operation of belt conveyors.

Information system meets the basic quality requirements, namely the responsibility for the nature and needs for quality management, speed, and frequency of information retrieval. The correctness and speed of decisions are the basis for ensuring the continuity of belt traffic.

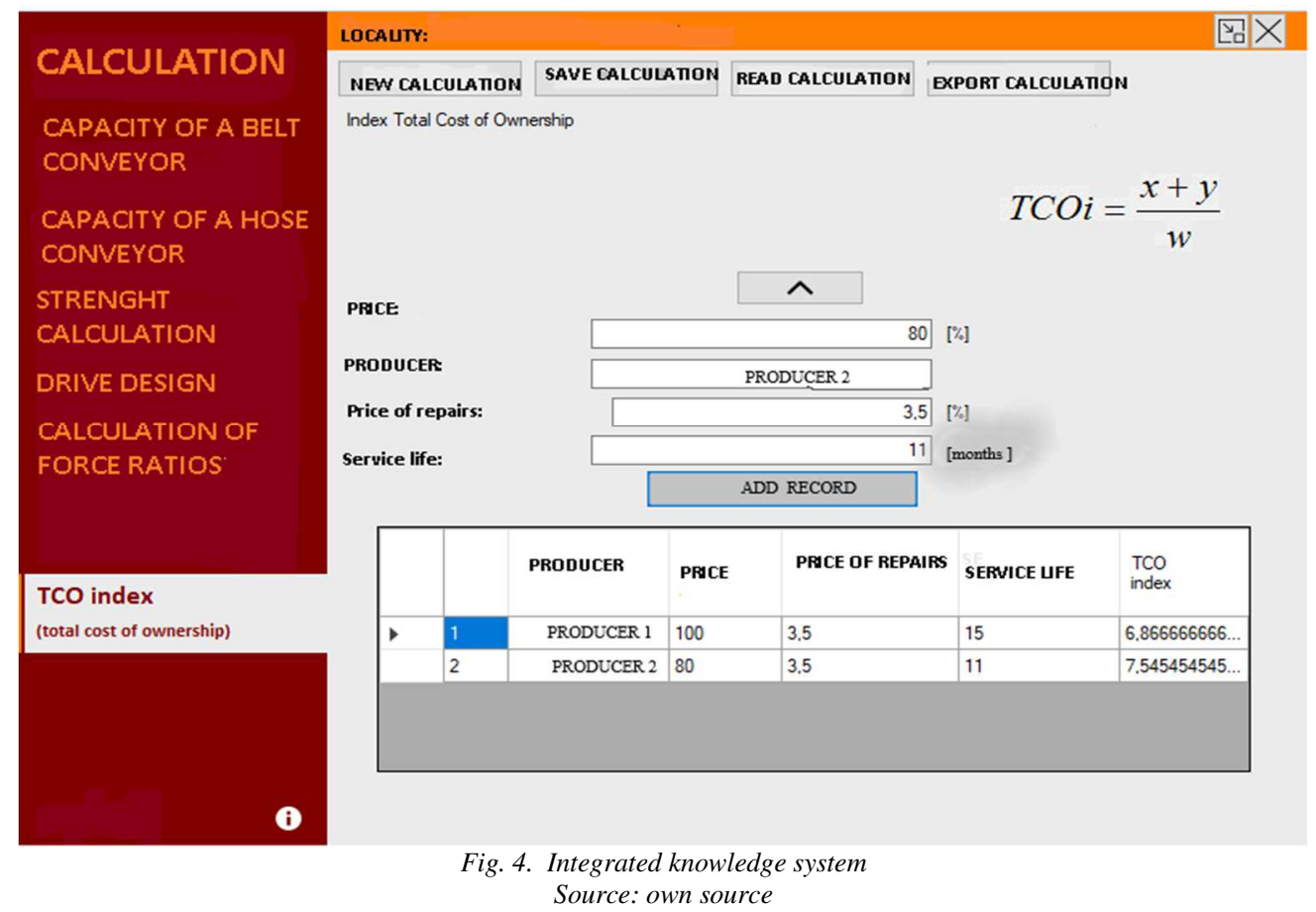

As part of the research, 40 conveyor belts were monitored. The basic parameters of selected conveyor belts (Table 2), the values of the TCO index are given in Table 3, which expresses the quality index for the purchase and use of the conveyer belt. At the same time, the quality of conveyor belts from two different manufacturers is compared. The conveyor belt is of better quality, which, based on the recalculation, shows lower values of the TCO index (by formula 1).

Tab. 2. Basic parameters of selected conveyors belts

\begin{tabular}{c|c|c|c|c|c|c}
\hline $\begin{array}{c}\text { Type of } \\
\text { belt } \\
\text { conveyor }\end{array}$ & $\begin{array}{c}\text { Cover } \\
\text { layers }\end{array}$ & $\begin{array}{c}\text { Length } \\
\text { of belt conveyor }[\mathrm{m}]\end{array}$ & $\begin{array}{c}\text { Width } \\
\text { of belt conveyor }[\mathrm{mm}]\end{array}$ & $\begin{array}{c}\text { Transported } \\
\text { material }\end{array}$ & $\begin{array}{c}\text { Grain size } \\
\text { of the } \\
\text { material } \\
{[\mathrm{mm}]}\end{array}$ & $\begin{array}{c}\text { Engine } \\
\text { power } \\
{[\mathrm{kW}]}\end{array}$ \\
\hline P1250/3 & 5+2D & 100 & 1200 & $\begin{array}{c}\text { Agglomerate, } \\
\text { additives }\end{array}$ & 150 & 50 \\
\hline P1250/3 & 5+2D & 130 & 1200 & $\begin{array}{c}\text { Agglomerate, } \\
\text { additives }\end{array}$ & 150 & 55 \\
\hline P1000/3 & 4+2A & 20 & 1000 & Agglomerate & $100-300$ & 50 \\
\hline P1000/3 & 4+2A & 24 & 1200 & Agglomerate & $100-300$ & 10 \\
\hline P1000/3 & 4+2A & 24 & 1200 & Agglomerate & $100-300$ & 10 \\
\hline P1000/3 & 4+2A & 15 & 1200 & Coke & $100-300$ & 50 \\
\hline
\end{tabular}




\begin{tabular}{c|c|c|c|c}
\multicolumn{5}{c}{ Tab. 3. Calculation TCO index for quality of belt conveyor } \\
\hline $\begin{array}{c}\text { Type of } \\
\text { belt } \\
\text { conveyor }\end{array}$ & $\begin{array}{c}\text { Service life } \\
\text { Producer 1 }\end{array}$ & $\begin{array}{c}\text { Service life } \\
\text { Producer 2 }\end{array}$ & $\begin{array}{c}\text { Index TCO } \\
\text { Producer 1 }\end{array}$ & $\begin{array}{c}\text { Index TCO } \\
\text { Producer 2 }\end{array}$ \\
\hline P1250/3 & 18.16 & 12 & 5.73 & 6.75 \\
\hline P1250/3 & 34.43 & 18.70 & 2.96 & 4.33 \\
\hline P1000/3 & 18.10 & 28.80 & 5.64 & 2.80 \\
\hline P1000/3 & 6.40 & 5.40 & 16.40 & 15.19 \\
\hline P1000/3 & 14.05 & 7.80 & 7.33 & 10.39 \\
\hline P1000/3 & 17.51 & 0.56 & 5.82 & 144.64 \\
\hline
\end{tabular}

This knowledge system for evaluating the quality of conveyor belts is a suitable tool for deciding on the selection of a suitable type of conveyor belt for specific operating conditions when accepting: characteristic properties of the transported material (grain size, sharpness, abrasiveness, temperature, specific weight, pour angle), track parameters (length, slope, convex or concave track shape, speed), the characteristics of the conveyor belt and its construction (tensile strength, permissible tensile stress, tensioning force, speed of the conveyor belt, the thickness of covering layers, number of inserts, the weight of the conveyor belt), parameters of the conveyor construction (number of rollers in the upper and lower branches of the conveyor, diameters of the drive and return drum, the spacing of roller stands, type of rollers).

\section{Discussion}

Based on the research carried out on conveyor belts, we can state that already during the individual phases of the development of conveyor belts, their service life and quality are defined. Great attention must therefore be paid to the quality, which is controlled by the certified system ISO 9001. Used technology, compliance with quality standards for input raw materials and materials (products), for example, for rubber compounds for the production of coatings (modulus of elasticity, length, thickness, weight), have a decisive influence on their quality. The influence of the production factor on the damage to the conveyor belt can be influenced as much as possible by the manufacturer himself. For each conveyor, it is necessary to select the correct tensile strength belt conveyors and the correct motor power of the conveyor drive from the point of view of service life. The nature of the transported material and its properties have a decisive influence on the wear and damage of the belt (fragmentation of the material, physical characteristics, and quantity). Reduction in grain size and sharpness can be eliminated by crushing. Special heat-resistant coatings are used for the transport of hot materials. In the case of conveyor belts for the transport of hot materials, they harden as a result of secondary vulcanization but also burn and separation of the individual layers of the DP structure. DP burns out if the loaded DP with hot material is parked for a long time. The presence of foreign objects in the transported material is another reason for its damage. This is a factor that the conveyor belt operator can eliminate, in particular by selecting the appropriate type of conveyor belt and designing the overflow site. The conveyor belt manufacturer can contribute to the elimination of the adverse effects of this factor by appropriate consultation and formulation of recommendations for users based on the implementation of experimental tests.

The construction of the conveyor and its technical condition contribute to up to $80 \%$ reduction of the life of the conveyor belts. These are mainly hoppers, side guides, cleaners and wiper systems, dirty surface of drums and support rollers, non-rotating rollers, etc. If the standards are not observed during storage, there is a loss of functional and operational properties. Conveyor belts should not be stored for more than 3 years. If the conveyor belt is stored for a long time in unsuitable spaces, it will crack and age, while the conveyor belt used for the same time shows only normal wear. Improper handling during storage, removal and assembly often causes damage. The joint is a critical point on the conveyor belt in terms of reliability, safety (Pacaiova, 2021), and service life of the conveyor belt. Reversing DP is not an often-used option to increase DP life, but it has its advantages. It can be used provided that the upper cover layer is no longer worn to the carcass) and the lower cover is still of sufficient thickness. Renovation is especially suitable for heavy types of DP, where the skeleton forms a substantial part of its price. Maintenance and monitoring are related to regular inspections of conveyor belts, regular replacement of damaged parts, and life monitoring. This factor significantly affects the degeneration processes of the rubbertextile conveyor belt, and its influence can be greatly influenced by the operator.

The methodology used has a key influence. Its appropriate choice significantly affects the operational economic aspects of belt transport. Operating devices also significantly affect the process of damaging the conveyor belt. This includes the effects of hopper, overflows, conveyor belt cleaners, support rollers, tensioning equipment, etc. The influence of service equipment on the process of gradual degradation of the rubber-textile conveyor belt can be corrected primarily by the operator, but in the initial phase of the design of the conveyor system, this process can also be corrected by the implementer or design component. The operating conditions are 
related to compliance with the prescribed belt load, tensioning method, operation automation, control method, environmental influences, and environmental requirements. This group of factors is influenced in the initial phase by the designer of the conveyor system, specifically by the selection of a suitable type of conveyor belt.

The installation affects the damage and service life of the conveyor belt during its placement on the conveyor. Improper installation can break the internal structure of the conveyor belt, which can gradually increase and lead to rupture of the conveyor belt. At the same time, during poor quality or unsystematically implemented installation may damage the basic structural elements of the belt conveyor (deflection of rollers, deformation of the supporting structure), which will result in incorrect guidance of the conveyor belt (its deflection and convergence from the support system) and result in increased damage to conveyor belt edges, etc.

The conveyor technology within which the conveyor belt is operated also represents an important factor influencing the process of damaging the conveyor belt. In case of inappropriate selection of a conveyor belt for specific transport technology, it is subject to systematic damage, which may end in its complete destruction. Similarly, the conveyor belt can be affected by ongoing changes that take place in the technological process without being taken into account in relation to the conveyor belt used. All these analyzed factors influence the level of quality of conveyor belts and have a significant impact on the evaluation of the performance of conveyor belts through key performance indicators (KPI).

\section{Conclusions}

The assessment of conveyor belts in terms of quality level depends on the economic care of the conveyor belts during their life cycle, taking into account their service life under the conditions of compliance with international standards. The evaluation of the performance of conveyor belts is carried out by means of KPI indicators, which are set to evaluate all factors that cause the causes of wear of conveyor belts in terms of technical, technological, economic, political. The creation of a knowledge system for conveyor belt quality assessment consists of a quality assessment subsystem from the design aspect, design of new procedures for product quality assessment of conveyor belts (number of inserts, cover layer thickness, carcass type, belt strength), design aspects of support systems: design of new procedures for the evaluation of DP product quality (classic support systems, new progressive support systems, new materials for the production of support systems, overflow parameters), creation of a comprehensive knowledge system of DP quality evaluation of the Ecotubelt type. The knowledge system enables the improvement of product, process, but above all, service quality of conveyor belts. Its main benefit for operators is the ability to keep accurate records of failures and repairs, the causes of failures, planned maintenance of DP, which is a prerequisite for evaluating the performance of conveyor belts during their life cycle. In the future, the given system should be extended to include the aspect of work safety, especially within the DP service quality subsystem due to the fact that each company must assess the risks in the company.

The result of the research of conveyor belts was the creation of a knowledge system that includes knowledge in the form of relevant and timely data for the decision-making process. The information we obtain in the process of operating conveyor belts can be collected, recorded, analyzed, evaluated, archived, and continuously used for effective management and decision-making in the created knowledge system. Knowledge makes it possible to monitor the performance of the process of the operational condition of the conveyor belt and monitor this process in terms of productivity, profitability, efficiency, effectiveness, the fulfilment of strategic goals. Knowledge management is a very important approach in terms of achieving the required level of quality of conveyor belts and their functional condition. The created knowledge system as a support tool for evaluating the quality of the conveyor belt is a prerequisite for sustainable quality and reducing the total operating costs to maintain the functional condition of the conveyor belt.

\section{References}

Ambrisko, L'., Marasova, D.(2017) Evaluation the Quality of Rubber Composites using the DOE Method. Quality - Access to Succes, 18(158) 60-63.

Ambrisko, L., Marasova, D., Grendel, P. (2016) Determination the effect of factors affecting the tensile strength of fabric conveyor belts. Eksploatacja i Niezawodnosc - Maintenance and Reliability. 18 (1) 110-116. DOI:10.17531/ein.2016.1.14

Andrejiova, M., Grincova, A., Marasova, D. (2018) Failure analysis of rubber composites under dynamic impact loading by logistic regression. Engineering Failure Analysis, 84, 311-319.

https://doi.org/10.1016/j.engfailanal.2017.11.019

Baldassarre, M.(2016) Think big: learning contexts, algorithms and data science. EM - Research on Education and Media. 8 (2). https://doi.org/10.1515/rem-2016-0020

Barburski, M. (2015) Analysis of the pipe conveyor belt pressure on the rollers on its circuit. Journal of Industrial Textiles, 45(6)1-16. https://doi.org/10.1177/1528083714567242 
Bednárová, L., Džuková, J., Grosoš, R., Gomory, M. and Petráš, M. (2020) Legislative instruments and their use in the management of raw materials in the Slovak Republic. Acta Montanistica Slovaca, 25 (1), 105-115. https://doi.org/10.46544/AMS.v25i1.10

Blazej, R. Bajda, M., Hardygora, M. (2017) Monitoring creep and stress relaxation in splices on multiply textile rubber conveyor belts. Acta Montanistica Slovaca. 22(2)116-125.

Bortnowski, P., Nowak-Szpak, A., Król, R., Ozdoba, M.(2021) Analysis and Distribution of Conveyor Belt Noise Sources under Laboratory Conditions. Sustainability. 3, 2233. https://doi.org/ 10.3390/su13042233

Bugaric, M. Tanasijevic, D. Polovina, D. Ignjatovic, P. Jovanovic (2012). Lost production cost of the over burden excavation system caused by rubber belt failure. Eksploatacja i Niezawodnosc-Maintenance and Reliability. 14 (4): 333-341.

Caban, L., Bokša, P., Marasová,D. (2016). Multi-criteria evaluation of conveyors with a closed conveyor. Transport and Logistics. 16(40)26-36.

Czaplicka, K.(2003) Eco-design of non-metallic layer composites with respect to conveyor belts. Materials and Design, 24(1)111-120. https://doi.org/10.1016/S0261-3069(02)00126-7

Girard, J. (2015): Defining knowledge management: Toward an applied compendium. Online Journal of Applied Knowledge Management A Publication of the International Institute for Applied Knowledge Management $3(1) 1-20$.

Gondek, H., Neruda, J., Pokorný, J. (2014) The dynamics of impacts tools the loading boom bucket wheel excavators(Conference Paper). Applied Mechanics and Materials, 683(1)213-218. https://doi.org/10.4028/www.scientific.net/AMM.683.213

Grincova, A., Berezny, S., Marasova, D. (2009) Regression model creation based on experimental tests of conveyor belts against belt rips resistance. Acta Montanistica Slovaca, 14 (1)113-120.

Grujic, M., Malindzak, D., Marasova, D. (2011) Possibilities for reducing the negative impact of the number of conveyors in a coal transportation system. Tehnicki vjesnik-technical gazette, 18(3)453-45 .

Hapla, T., Gabrehelova,L., Fries, J. (2013) Inovace presypových stanic pro eliminace poruch dopravniho pasu. Transfer inovaci. 25, 67-70.

Hardygora, M., Bajda, M., Blazej, R. (2015) Laboratory testing of conveyor textile belt joints used in underground mines. Mining Science, 22(1)161-169.

Hilson, G. (2003) Defining "cleaner production" and "pollution prevention" in the mining context. Minerals Engineering Volume: 16 Issue: 4 Pages: $305-32$. https://www.matadorbelts.com/pages/special_application/ecotubelt/ecotubelt_sk.html

Ladányi, G. (2016) Study on the noise emission of belt conveyor idler rolls. Ann. Univ. Petrosani Mechanic Engineering, 18, 83-92.

Lukáč, S., Marasová, D., Mikušová, N., Stopka, O. (2020) Quality management of information systems. Quality Access to Success. 21(174)167-170.

Lukáč, S., Mikušová, N. (2019) Virtualization as a logistics support for enterprise management. Transport \& Logistics.46(1)22-27 http://people.fberg.tuke.sk/tnl/index.php/tnl/article/view/45/19...

Mahmood, Tahir; Ali, Zeeshan (2021) A novel approach of complex q-rung orthopair fuzzy hamacher aggregation operators and their application for cleaner production assessment in gold mines. Journal of ambient intelligence and humanized computing. https://doi.org/10.1007/s12652-020-02697-2

Menegaki, M., Damigos, D. (2020) A systematic review of the use of environmental economics in the mining industry. Journal of Sustainable Mining. 19(4). https://doi.org/10.46873/2300-3960.1034

Monster belt: Pipe conveyors. Dostupné na internete: [online]. [s.a.]. [cit. 2018-10-02]. http://www.monsterbelt.com/special-conveyor.

Moreau, K, Laamanen, C., Bose, R., Shang, H., Scott, J.(2020) Life cycle assessment to demonstrate how automation improves the sustainability performance of an underground mining operation. Journal of Sustainable Mining. 19(3). https://doi.org/10.46873/2300-3960.1016.

Sawicki, W.; Król, R. (2006) Estimation of vibro-acoustic properties of idlers based on modal analysis. Mining Science, 8, 179.

Sazambayeva, B. T.; Samogin, Y. N.; Togizbayeva, B. B.; et al.(2020): In reference to the research of pipe belt conveyor. Bulletin of the national academy of sciences of the republic of Kazakhstan, 6(1) 19-27. DOI: $10.32014 / 2020.2518-1467.178$

Syed, A., Sabir, M.R., Sarmad Ejaz, S., Sohail, H. (2020) Direct and Indirect effect of Knowledge Management Practices on Firm Innovation via Knowledge Application. International Review of Management and Marketing 10(4).DOI: 110-118 DOI: 10.32479/irmm.10196

Wang, Shuang; Li, Deyong; Hu, Kun (2019) Analysis and Experimental Study on Pressure Characteristics of Supporting Roller Group of Pipe Belt Conveyor. Shock and Vibration. 1(7061847).

Zamiralova M.E. (2017) Design aspects of pipe belt conveyors. DOI: 10.4233/uuid:a989069c-54e4-4d80-a30aa6fb9b333287. 
Pacaiová, H., Andrejiová, M., Balažiková, M., Tomašková, M., Gazda, T., Chomová, K., Hijj, J., Salaj, L. (2021) Methodology for Complex Efficiency Evaluation of Machinery Safety Measures in a Production Organization. Applied Sciences, 11 (1) 1-16. https://doi.org/10.3390/app11010453. 